www.jmscr.igmpublication.org

Index Copernicus Value: 79.54

ISSN (e)-2347-176x ISSN (p) 2455-0450

crossref DOI: https://dx.doi.org/10.18535/jmscr/v7i5.64

\title{
To study the effect of high density lipoprotein and calcium on the levels of random blood sugar, body mass index, and age: A case control perspective
}

\author{
Authors \\ Dr Amitabh Agarwal ${ }^{1}$, Dr Prabhakar Singh Bais ${ }^{1}$ * \\ ${ }^{1}$ Associate Professor, Department of Physiology, T. S. M. Medical College \& Hospital, Lucknow, \\ Uttar Pradesh, India \\ Email: dramitabhagarwal@yahoo.com, 9780851106 \\ ${ }^{1 *}$ Assistant Professor, Head of the Department, Biochemistry Department, MLB Medical College, Jhansi \\ *Corresponding Author \\ Dr Prabhakar Singh Bais \\ Assistant Professor, Head of the Department, Biochemistry Department, MLB Medical College, Jhansi
}

\begin{abstract}
Type 2 Diabetes Mellitus (T2DM) is a disorder in which there is inefficient use of insulin hormone, leads to build up of glucose in the blood and eventually ends up with hyperglycemia. The aim of this study was to test the hypothesis of inter-relationship of age, body mass index (BMI), random blood sugar (RBS), Total Cholesterol (TC), Triacylglycerols (TAGs), High Density Lipoproteins cholesterol (HDLc), and Ca in patients with T2DM and also to compare these levels with that of healthy controls. Plasma glucose, serum TC, TAGs, HDLc, and Ca were estimated according to the instructions given in the methods. BMI was significantly higher and also the levels of RBS, TC and TAGs were significantly higher in T2DM patients compared with healthy controls. In addition, total serum Ca level was significantly higher in T2DM patients compared with healthy controls. No significant differences were observed in age and HDLc levels in T2DM patients compared with healthy controls. In the patient group positive correlation was observed between age and TAGs, age and HDLc, RBS and TC, RBS and TAGs, RBS and HDLc. In the control group, we found positive correlation between age and HDLc and a negative correlation between BMI and serum Ca. The authors conclude from the study that alterations in the study parameters in T2DM group are due to hyperglycemia, deficient scavenging action of HDLc and increase in serum calcium. Therefore, in patients with T2DM, any compensation mechanism may become insufficient.
\end{abstract}

\section{Introduction}

Type 2 Diabetes Mellitus (T2DM) is a disorder in which there is inefficient use of insulin hormone, which leads to build up of glucose in the blood and eventually ends up with hyperglycemia ${ }^{[1]}$. The risk of T2DM occurrence increases in an individual with genetic predisposition present in the family; if female gender; and also in ageing $^{[2,3]}$. The contributing factors other than that of genetic factors include are diet, environmental pollutants, cigarette smoking, and obesity. Urbanization has urged the people to a diverted dietary intake ${ }^{[1-3]}$, which accompanied with lack of exercise and improper sleep have alter the physiological responses of the cell to experience hyperglycemia $^{[4]}$. Recent international diabetes 
federation reports that there are around 1 billion adults are overweight worldwide, and 300 million of them are obese $\mathrm{e}^{[5]}$. Most of the individuals included in the report have adopted the lifestyle of physical inactivity and western lifestyle, and most prominently India facing the greatest increase in the count of T2DM individuals ${ }^{[5,6]}$. The major disheartening problem is that overweight and obesity have a strong relationship towards atherosclerosis, cardio-vascular and cerebrovascular accidents ${ }^{[7]}$. Thus, the research should be given high priority in a way to understand the factors that are solely responsible for the causation of obesity and also to know the preventive measures.

Recent reports have also suggests that the contributing factors have their affect on biomolecules metabolism ${ }^{[8-10]}$. Normally insulin is released by the beta cells of pancreas in response to glucose present in the blood ${ }^{[11,12]}$. The released insulin sensitizes the insulin dependent tissues like skeletal muscle, adipose tissue, and liver to take up glucose for further metabolism ${ }^{[8-12]}$. But, chronic persistence of elevated glucose levels (hyperglycemia) impairs insulin stimulated glucose utilization in skeletal muscles and adipose tissues, leads to glucose toxicity ${ }^{[13]}$. Further, improper uptake of glucose, also activates Hydroxyl Methyl Glutaryl Coenzyme-A (HMGCo-A) reductase, and decreases the oxidation of Triacylglycerols (TAG) at the extra-hepatic tissues resulting in increase of plasma glucose concentration and dyslipidemia in $\mathrm{T} 2 \mathrm{DM}^{[14]}$.

The important function of High Density Lipoprotein cholesterol (HDLc) is to remove fats and cholesterol from extra-hepatic cells and transport it back to the liver for excretion or reutilization $^{[15]}$. Lower levels of HDLc are consistently associated with increased risk of T2DM and also cardiovascular diseases and higher levels of HDLc are correlated with better cardiovascular health in reports ${ }^{[15-17]}$. Studies have also suggested that HDLc improves insulin secretion and also regulate the glucose levels in the animals ${ }^{[18-20]}$. There are also experimental evidences which suggest that levels of HDLc may contribute to the etio-pathogenesis of $\mathrm{T} 2 \mathrm{DM}^{[17-19]}$. Calcium $(\mathrm{Ca})$ is an element that plays an important role not only in cell signaling as second messenger but also in a wide range of biological functions ${ }^{[20]}$. In recent decades, it has been shown that $\mathrm{Ca}$ is related to insulin secretion, and insulin resistance ${ }^{[21]}$. Insulin secretion has been shown with respect to intracellular calcium which increases the expression of glucose transporters on insulin sensitive cells ${ }^{[22]}$. Studies have also shown association of elevated level of serum calcium with plasma glucose $\mathrm{e}^{[21-24]}$.

The above cited literature demonstrates that HDLc and $\mathrm{Ca}$ help in the secretion insulin, transport of glucose from outside to inside of the cell, and also in the utilization of glucose in the body respectively. More important function of HDLc is to scavenge the extra hepatic cholesterol to the liver.

Therefore in view of above-cited results, the aim of this study was to test the hypothesis of interrelationship of age, body mass index (BMI), random blood sugar (RBS), TC, TAGs, HDLc and $\mathrm{Ca}$ in patients with T2DM and also to compare these levels with that of healthy controls.

\section{Material \& Methods}

The study was conducted in the Department of Biochemistry, Maharani Laxmi Bai Medical College (MLBMC), Jhansi. Age \& sex matched fifty human individuals having a normal glycaemic status were taken into healthy control group. Fifty T2DM subject, on treatment were included in T2DM group. The diagnosis of T2DM was made according to the norms laid by American Diabetes Association 2018. The diagnosis of T2DM group subjects was done by the consultants of General Medicine department of MLBMC. Exclusion criteria were type 1 diabetes individuals, less than five years of known duration of T2DM, and with complications. Inclusion criteria for healthy controls were nondiabetic, not taking supplementations, and having no other complications. Plasma glucose was 
estimated by using the method Glucose Oxidase and Peroxidase (DPEC - GOD/POD) purchased from Arkray Healthcare Pvt. Ltd. Serum TC was estimated by using the method of Cholesterol Oxidase and Peroxidase (CHOD/POD) purchased from Arkray Healthcare Pvt. Ltd. Serum TAGs was estimated by using the method Glycerol Phosphate Oxidase and Peroxidase (Liquid stable) purchased from Arkray Healthcare Pvt. Ltd. Serum HDL was estimated by using the method polyethylene glycol (PEG) and phenol and 4aminoantipyrine (PAP). Serum Calcium (Ca) was estimated by Arseno III method. Fasting venous blood $(5 \mathrm{ml})$ were drawn into EDTA and plane vials, after informed written consent from all the study group subjects with a disposable syringe \& needle, under all aseptic conditions. Serum was separated by centrifuging the blood at $3000 \mathrm{rpm}$ for 20 minutes. Samples were stored in aliquots at $-20^{\circ} \mathrm{C}$ until assayed.

\section{Statistical Analysis}

IBM SPSS version 20 was used to perform statistical analysis. Unpaired ' $t$ ' test was performed to compare the means of variables between two groups. Pearson correlation coefficient was considered to understand the association between two variables. Percentages were also calculated. $\mathrm{P}<0.05$ was considered significant.

\section{Results}

Age, BMI, RBS, TC, TAGs, HDLc and serum Ca levels are shown in Table 1. BMI was significantly higher and also the levels of RBS, TC $(\mathrm{t}=5.043, \mathrm{~d}=98)$ and TAGs $(\mathrm{t}=2.419, \mathrm{~d}=98)$ were significantly higher in T2DM patients compared with healthy controls. In addition, Total serum Ca ( $\mathrm{t}=18.642$, $\mathrm{d}=98)$ level was significantly higher in T2DM patients compared with healthy controls. No significant differences were observed in age and HDLc levels in T2DM patients compared with healthy controls.

In the patient group (Table 2) positive correlation was observed between age and TAGs $(\mathrm{R}=0.3458$, $\mathrm{P}=0.01)$, age and HDLc $(\mathrm{R}=0.1401, \mathrm{P}=0.03)$, RBS and TC $(\mathrm{R}=0.3770, \mathrm{P}=0.03), \mathrm{RBS}$ and TAGs $(\mathrm{R}=0.1241, \mathrm{P}=0.01)$, RBS and HDLc $(\mathrm{R}=0.2060$, $\mathrm{P}=0.02$ ). In the control group (Table 3), we found positive correlation between age and HDLc $(\mathrm{R}=0.2655, \mathrm{P}=0.01)$ and a negative correlation between $\mathrm{BMI}$ and serum $\mathrm{Ca}(\mathrm{R}=-0.613, \mathrm{P}=0.034)$.

Table 1: Findings in patients with T2DM and healthy control groups

\begin{tabular}{|l|c|c|c|}
\hline Variable & T2DM subjects $(\mathbf{n = 5 0})$ & Control subjects $(\mathbf{n = 5 0})$ & P-value \\
\hline Age $($ years $)$ & $51.9 \pm 7.2$ & $51 \pm 4.7$ & $\mathrm{NS}$ \\
\hline BMI $\left(\mathrm{kg} / \mathrm{mt}^{2}\right)$ & $30.1 \pm 4.2$ & $24.1 \pm 2.2$ & $\mathrm{~S}$ \\
\hline RBS $(\mathrm{mg} / \mathrm{dL})$ & $195.7 \pm 61.8$ & $125.9 \pm 11.4$ & $\mathrm{~S}$ \\
\hline TC $(\mathrm{mg} / \mathrm{dL})$ & $168.5 \pm 27.7$ & $146.6 \pm 12.9$ & $\mathrm{~S}$ \\
\hline TAGs $(\mathrm{mg} / \mathrm{dL})$ & $159.9 \pm 55.4$ & $139.6 \pm 21.4$ & $\mathrm{~S}$ \\
\hline HDLc $(\mathrm{mg} / \mathrm{dL})$ & $41.2 \pm 4.6$ & $45.8 \pm 3.4$ & $\mathrm{NS}$ \\
\hline Total Ca $(\mathrm{mg} / \mathrm{dL})$ & $10.2 \pm 0.8$ & $9.1 \pm 0.2$ & $\mathrm{~S}$ \\
\hline
\end{tabular}

Note: BMI- body mass index, Random Blood Sugar (RBS), TC-Total Cholesterol, TAGs-Triacylglycerols, HDLc-High Density Lipoprotein cholesterol, Calcium (Ca), S-Significant $(<0.05)$, NS-Not Significant $(>0.05)$

Table 2: Pearson correlation in T2DM group

\begin{tabular}{|l|c|c|c|}
\hline Variables & Age & Body Mass Index & Random Blood Sugar \\
\hline Age (Years) & --- & $\mathrm{R}=-0.0584$ & $\mathrm{R}=0.3088$ \\
\hline Body Mass Index & $\mathrm{R}=-0.0584$ & ---- & $\mathrm{R}=0.1243$ \\
\hline Total Cholesterol & $\mathrm{R}=-0.1142$ & $\mathrm{R}=-0.0960$ & $\mathrm{R}=0.3770$ \\
\hline Triacylglycerols & $\mathrm{R}=0.3458$ & $\mathrm{R}=0.0391$ & $\mathrm{R}=0.1241$ \\
\hline High Density Lipoprotein & $\mathrm{R}=0.1401$ & $\mathrm{R}=-0.1617$ & $\mathrm{R}=0.2060$ \\
\hline Serum Total calcium & $\mathrm{R}=-0.124$ & $\mathrm{R}=-0.0826$ & $\mathrm{R}=-0.0677$ \\
\hline
\end{tabular}


Table 3: Pearson correlation in Control group

\begin{tabular}{|l|c|c|c|}
\hline Variables & Age & Body Mass Index & Random Blood Sugar \\
\hline Age (Years) & --- & $\mathrm{R}=-0.1279$ & $\mathrm{R}=0.1494$ \\
\hline Body Mass Index (BMI) & $\mathrm{R}=-0.1279$ & ---- & $\mathrm{R}=-0.3293$ \\
\hline Total Cholesterol & $\mathrm{R}=-0.1427$ & $\mathrm{R}=0.1965$ & $\mathrm{R}=0.1027$ \\
\hline Triacylglycerols & $\mathrm{R}=-0.1091$ & $\mathrm{R}=-0.0451$ & $\mathrm{R}=0.2049$ \\
\hline High Density Lipoprotein & $\mathrm{R}=0.2655$ & $\mathrm{R}=0.0981$ & $\mathrm{R}=0.1233$ \\
\hline Serum Total calcium & $\mathrm{R}=0.1704$ & $\mathrm{R}=-0.0588$ & $\mathrm{R}=-0.1808$ \\
\hline
\end{tabular}

Figure 1: Pie chart depicting the gender distribution of subjects of T2DM group

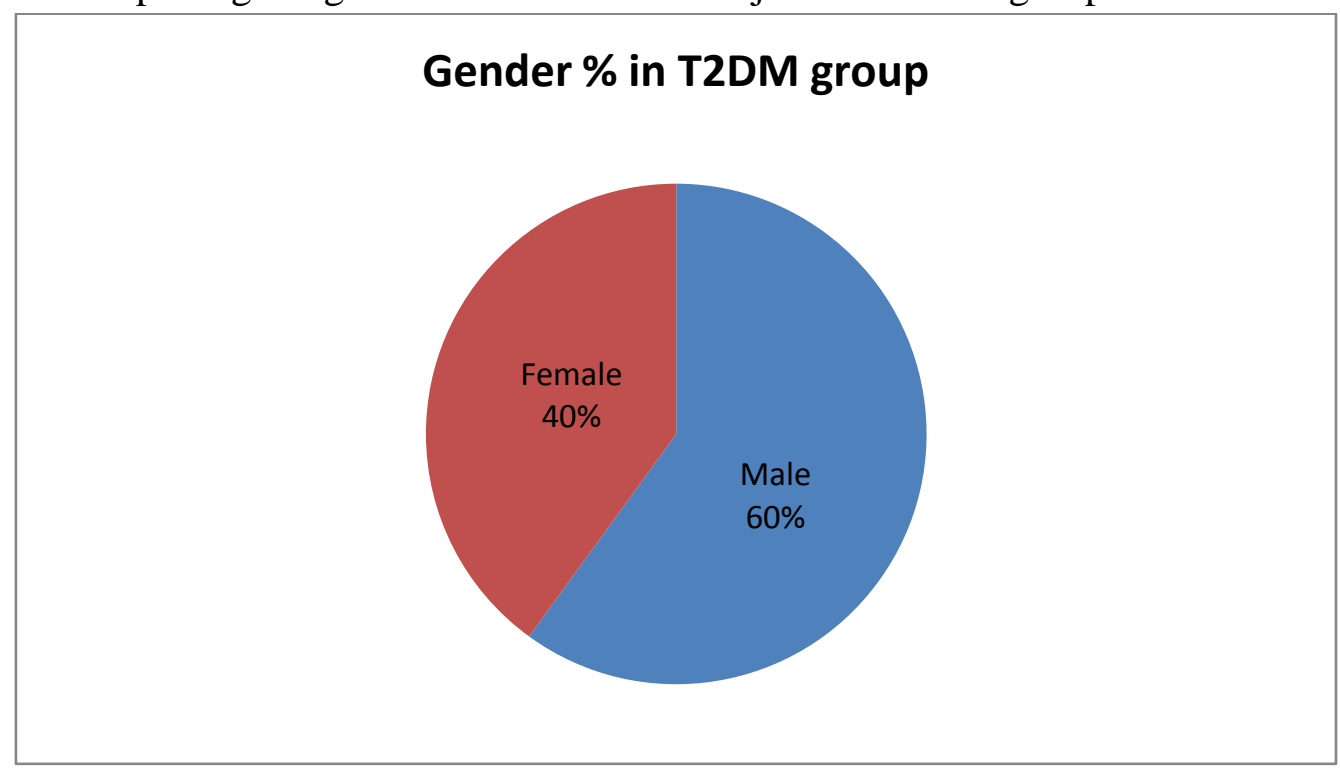

Figure 2: Pie chart depicting the gender distribution of Control subjects group

\section{Gender \% in Control group}

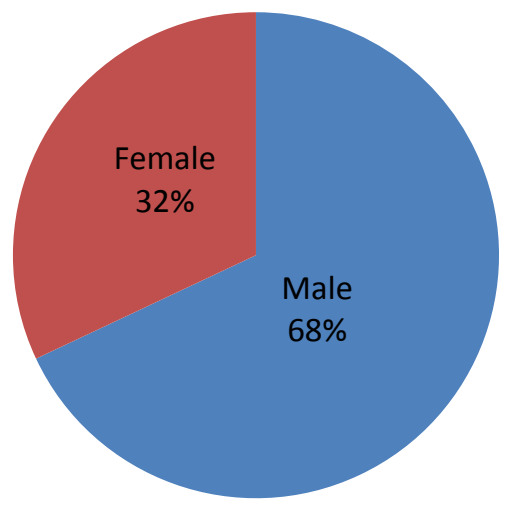

\section{Discussion}

Statistical significant differences were observed in BMI and in the levels of TC, TAGs, and Ca when compared between T2DM patients and healthy control. On the contrary, in the present study we did not observe statistical significant in the age group and also in the levels of HDLc when compared between T2DM patients and healthy control. In the patient group (Table $3 \& 4$ ) positive correlation was observed between age and TAGs, RBS and TC, RBS and TAGs, RBS and HDLc. T2DM is a common metabolic 
disorder associated with profound alteration in lipid and lipoprotein profiles ${ }^{[25,26]}$. Hyperglycemia affects lipids by increasing the genes of key enzymes responsible for lipid metabolism ${ }^{[14,25-28]}$. The present study observed dyslipidemia in human. Previous studies have shown that in several models of T2DM including humans, lipoatrophic mice overexpressing SREBP-1c in adipose tissue, and insulin receptor substrate-2 (IRS-2) knockout mice in which insulin signaling is somehow impaired, hepatic SREBP-1c lipogenic transcription factors expression is instead activated ${ }^{[29,30]}$. A study demonstrated in insulin-depleted, STZ-administered mice that SREBP-1c induction does not require insulin ${ }^{[31]}$. Thus, continuous availability of glucose increased the formation of TC and TAG levels in the present study. HDLc is a lipoprotein, which carries cholesterol to the liver and transfer TAGs to other lipoproteins. Insulin is known to promote apolipoprotein A and HDL biosynthesis by liver [32,33]. Hyperglycemia inhibits this process and thus HDL secretion is impaired ${ }^{[34]}$. In addition, derangement in anabolic process i.e. more synthesis (cholesterol) and less utilization (TAGs) as observed in T2DM patients, is likely to cause decrease in the HDLc level ${ }^{[35]}$. Previous findings also demonstrated hyperglycemia and dyslipidemia in T2DM and different diabetic animal models ${ }^{[32-35]}$. Hyperglycemia induces alteration in weight in humans and as well as in rodents $^{[35-37]}$. Studies on T2DM individuals and T2DM animal models have been shown to associate with body mass and hyperglycemia ${ }^{[38,39]}$. In the current study, we observed higher BMI in T2DM subjects. In the studies ${ }^{[35-39]}$, it is not clearly stated whether T2DM comes first or change in the BMI. Nonetheless, the present study observed an increase in BMI compared to healthy controls. Studies revealed that increase weight can affect diabetes and diabetes can affect weight [40,41]. Overweight individuals particularly when body fat is distributed in the abdominal or visceral fat region, are associated with several metabolic abnormalities and diseases, including $\mathrm{T} 2 \mathrm{DM}^{[42]}$.
Even $10 \%$ increase in weight during their midlife enhances the risk of developing T2DM by more than 15 times when compared to a weight gain of after the young age ${ }^{[43]}$. Studies also demonstrate that weight loss through lifestyle intervention improved glycemic status and was effective in preventing the further development of diabetes ${ }^{[42,44,45]}$. Therefore, the increased scale between diabetes and BMI was due to hyperglycemia.

HDL particles export excessive lipid molecules present in the extra hepatic tissues to the liver for their further fate ${ }^{[15]}$. Such lipid molecules include cholesterol, phospholipid, and $\mathrm{TAGs}^{[15]}$. In the present study, we observed significant increase in TAGs in T2DM group as compared to control group TAGs. In addition, it is interesting that a correlation between age and HDLc was positive in the T2DM group but negative in the control group. At first the correlation between age and HDLc observed in the two groups seem contradictory, but possible explanation could be that the increase in HDLc and the TAG is compensatory to the increase in age. However, this increase is insufficient because T2DM have lower HDLc levels than their age-matched controls. There are many possible interpretations of this correlation in patients with T2DM because of the multifaceted pathogenesis of the disease. Lower level of HDLc was observed in the studies [15-20]. The studies also observed that individuals with T2DM are affected with vascular diseases in relation to lower HDLc levels ${ }^{[16-18]}$. In fact, the studies have referred lower level of HDLc to genetic factors, smoking, alcohol consumption and duration of the disease ${ }^{[18-20]}$, but we attribute the lower HDLc level of the present study subjects to higher BMI as we observed increase in BMI in T2DM group subjects when compared to control group subjects. The fact that some variables affecting the status of HDLc were not controlled, e.g., age, the onset and duration of the disease, physical activity, and could be a limitation to our study, but the results were in accordance with previous research $^{[18-20,35-39]}$. However, we tried to overcome this handicap by taking blood samples 
from all patients at the same time irrespective of physical activity of the subjects involved in the study.

In the present study we observed significant difference in the level of serum calcium (Ca) in T2DM group subjects when compared with control group subjects. Previous studies have reported that serum total calcium levels are higher in individuals with diabetes than in those without [21-24]. In addition, the current study observed negative correlation in $\mathrm{BMI}$ and serum $\mathrm{Ca}$ in control subjects. The secretion of insulin in response to an elevated concentration of plasma glucose is a $\mathrm{Ca}^{2+}$-dependent process ${ }^{[22]}$. Alterations in insulin secretion have also been involved with disorders in blood glucose homeostasis ${ }^{[22,23]}$, which was observed in the form of hyperglycemia in the present study. Thus, increase in serum $\mathrm{Ca}$ in T2DM subjects infers that the increase in $\mathrm{BMI}$ in order to compensate the metabolism of increased TC, TAGs in T2DM subjects. Subsequently, enhanced Ca levels can decrease the expression of glucose transporters and reduce glucose intake and, as a result, increase glucose plasma concentrations. Therefore, further studies are extensively needed on a multicountric, multicentric which should include all ethnic population to understand the mechanisms involved between serum calcium homeostasis, insulin, and glucose metabolism.

\section{Conclusion}

The authors conclude from the study that alterations in the study parameters in T2DM group are due to hyperglycemia, deficient scavenging action of HDLc and increase in serum $\mathrm{Ca}$. Therefore, in patients with T2DM, any compensation mechanism may become insufficient. Studies have reported the beneficial effects of HDLc and $\mathrm{Ca}$ in humans but it has not been extensively studied in a multicountric, multicentric which should include all ethnic population.

Conflict of Interest: None declared.

\section{References}

1. Triplitt CL. Examining the mechanisms of glucose regulation. American Journal of Managed Care. 2012 Jan;18(1):S4.

2. Kolluru GK, Bir SC, Kevil CG. Endothelial dysfunction and diabetes: effects on angiogenesis, vascular remodeling, and wound healing. International journal of vascular medicine. 2012;2012.

3. Mastrandrea LD, Quattrin T. Clinical evaluation of inhaled insulin. Advanced drug delivery reviews. 2006 Oct 31;58(910):1061-75.

4. Boutcher SH, Dunn SL. Factors that may impede the weight loss response to exercise-based interventions. Obesity Reviews. 2009 Nov;10(6):671-80.

5. Atlas D. International diabetes federation. IDF Diabetes Atlas, 7th edn. Brussels, Belgium: International Diabetes Federation. 2015.

6. Seidell JC. Obesity, insulin resistance and diabetes - a worldwide epidemic. British Journal of Nutrition. 2000 Jun;83(S1):S58.

7. Sanz M, Ceriello A, Buysschaert M, Chapple I, Demmer RT, Graziani F, Herrera D, Jepsen S, Lione L, Madianos P, Mathur M. Scientific evidence on the links between periodontal diseases and diabetes: Consensus report and guidelines of the joint workshop on periodontal diseases and diabetes by the International Diabetes Federation and the European Federation of Periodontology. Diabetes research and clinical practice. 2018 Mar 1;137:231-41.

8. Pacifici RE, Davies KJ. Protein, lipid and DNA repair systems in oxidative stress: the free-radical theory of aging revisited. Gerontology. 1991;37(1-3):166-80.

9. Jung U, Choi MS. Obesity and its metabolic complications: the role of adipokines and the relationship between obesity, inflammation, insulin resistance, dyslipidemia and nonalcoholic fatty liver 
disease. International journal of molecular sciences. 2014;15(4):6184-223.

10. Shulman GI. Ectopic fat in insulin resistance, dyslipidemia, and cardiometabolic disease. New England Journal of Medicine. 2014 Sep 18;371(12):1131-41.

11. Saltiel AR, Kahn CR. Insulin signalling and the regulation of glucose and lipid metabolism. Nature. 2001 Dec 13;414(6865):799.

12. Röder PV, Wu B, Liu Y, Han W. Pancreatic regulation of glucose homeostasis. Experimental \& molecular medicine. 2016 Mar;48(3):e219.

13. Singh VK, Sarkar SK, Saxena A, Koner BC. Sub-toxic exposure to lindane activates redox sensitive kinases and impairs insulin signaling in muscle cell culture: The possible mechanism of lindane-induced insulin resistance. Toxicology in Vitro. 2019 Feb 1;54:98104.

14. Friesen JA, Rodwell VW. The 3-hydroxy3-methylglutaryl coenzyme-A (HMGCoA) reductases. Genome biology. 2004 Oct;5(11):248.

15. Schmidt MI, Duncan BB, Bang H, Pankow JS, Ballantyne CM, Golden SH, Folsom AR, Chambless LE. The Atherosclerosis Risk in Communities Investigators. Identifying individuals at high risk for diabetes: the Atherosclerosis Risk in Communities study. Diabetes Care. 2005;28:2013-8.

16. Wilson PW, Meigs JB, Sullivan L, Fox CS, Nathan DM, D'Agostino RB. Prediction of incident diabetes mellitus in middle-aged adults: the Framingham Offspring Study. Archives of internal medicine. 2007 May 28;167(10):1068-74.

17. Siebel AL, Natoli AK, Yap FY, Carey AL, Reddy-Luthmoodoo M, Sviridov D, Weber CI, Meneses-Lorente G, Maugeais C, Forbes JM, Kingwell BA. Effects of high-density lipoprotein elevation with cholesteryl ester transfer protein inhibition on insulin secretion. Circulation research. 2013 Jul 5;113(2):167-75.

18. Drew BG, Rye KA, Duffy SJ, Barter P, Kingwell BA. The emerging role of HDL in glucose metabolism. Nature Reviews Endocrinology. 2012 Apr;8(4):237.

19. Drew BG, Duffy SJ, Formosa MF, Natoli AK, Henstridge DC, Penfold SA, Thomas WG, Mukhamedova N, de Courten B, Forbes JM, Yap FY. High-density lipoprotein modulates glucose metabolism in patients with type 2 diabetes mellitus. Circulation. 2009 Apr 21;119(15):2103.

20. Fryirs MA, Barter PJ, Appavoo M, Tuch BE, Tabet F, Heather AK, Rye KA. Effects of high-density lipoproteins on pancreatic $\beta$-cell insulin secretion. Arteriosclerosis, thrombosis, and vascular biology. 2010 Aug 1;30(8):1642-8.

21. Danaei G, Lu Y, Singh G, Stevens G, Cowan M, Farzadfar F, Lin J, Finucane M, Rao M, Khang Y, Riley L. Cardiovascular disease, chronic kidney disease, and diabetes mortality burden of cardiometabolic risk factors from 1980 to 2010: a comparative risk assessment.

22. Peacock M. Calcium metabolism in health and disease. Clinical Journal of the American Society of Nephrology. 2010 Jan 1;5(Supplement 1):S23-30.

23. Mears D. Regulation of insulin secretion in islets of Langerhans by $\mathrm{Ca} 2+$ channels. The Journal of membrane biology. 2004 Jul 1;200(2):57-66.

24. Levy J, Stern Z, Gutman A, Naparstek Y, Gavin JR, Avioli LV. Plasma calcium and phosphate levels in an adult noninsulindependent diabetic population. Calcified tissue international. 1986 Sep 1;39(5):3168.

25. DeFronzo, R. A. (2009) From the triumvirate to the ominous octet: a new par-adigm for the treatment of type 2 diabetes mellitus. Diabetes 58, 773-795. 
26. Stadler K, Goldberg IJ, Susztak K. The evolving understanding of the contribution of lipid metabolism to diabetic kidney disease. Current diabetes reports. $2015 \mathrm{Jul}$ 1;15(7):40.

27. Okin D, Medzhitov R. The effect of sustained inflammation on hepatic mevalonate pathway results in hyperglycemia. Cell. 2016 Apr 7;165(2):343-56.

28. Pozzo L, Vornoli A, Coppola I, Della Croce CM, Giorgetti L, Gervasi PG, Longo V. Effect of HFD/STZ on expression of genes involved in lipid, cholesterol and glucose metabolism in rats. Life sciences. 2016 Dec 1;166:149-56.

29. Stern JH, Rutkowski JM, Scherer PE. Adiponectin, leptin, and fatty acids in the maintenance of metabolic homeostasis through adipose tissue crosstalk. Cell metabolism. 2016 May 10;23(5):770-84.

30. Morton GJ, Schwartz MW. Leptin and the central nervous system control of glucose metabolism. Physiological reviews. 2011 Apr;91(2):389-411.

31. Matsuzaka T, Shimano H, Yahagi N, Amemiya-Kudo M, Okazaki H, Tamura Y, Iizuka Y, Ohashi K, Tomita S, Sekiya M, Hasty A. Insulin-independent induction of sterol regulatory element-binding protein1c expression in the livers of streptozotocin-treated mice. Diabetes. 2004 Mar 1;53(3):560-9.

32. Kardassis D, Gafencu A, Zannis VI, Davalos A. Regulation of HDL genes: transcriptional, posttranscriptional, and posttranslational. InHigh Density Lipoproteins 2015 (pp. 113-179). Springer, Cham.

33. Arya N, Kharjul MD, Shishoo CJ, Thakare VN, Jain KS. Some molecular targets for antihyperlipidemic drug research. European journal of medicinal chemistry. 2014 Oct 6;85:535-68.
34. Jellinger PS. Metabolic consequences of hyperglycemia and insulin resistance. Clinical cornerstone. 2007 Jan 1;8:S30-42.

35. Doddigarla Z, Parwez I, Abidi S, Ahmad J. Effect of Melatonin and Chromium Picolinate Administration to High Carbohydrate Diet-Fed Male Wistar Rats. Journal of Molecular and Genetic Medicine. 2017;11:1-7.

36. Capobianco E, Fornes D, Linenberg I, Powell TL, Jansson T, Jawerbaum A. A novel rat model of gestational diabetes induced by intrauterine programming is associated with alterations in placental signaling and fetal overgrowth. Molecular and cellular endocrinology. 2016 Feb 15;422:221-32.

37. Doddigarla Z, Ahmad J, Parwez I. Effect of chromium picolinate and melatonin either in single or in a combination in high carbohydrate diet-fed male Wistar rats. Biofactors. 2016 Jan;42(1):106-14.

38. Sundaram, B., Aggarwal, A., and Sandhir, R. (2013) Chromium picolinate attenuates hyperglycemia-induced oxidative stress in streptozotocin-induced diabetic rats. J. Trace Elem. Med. Biol. 27, 117-121.

39. Marmett B, Nunes RB. Effects of chromium picolinate supplementation on control of metabolic variables: A systematic review. J Food Nutr Research. 2016;4:633-9.

40. Brunner S, Stecher L, Ziebarth S, Nehring I, Rifas-Shiman SL, Sommer C, Hauner H, von Kries R. Excessive gestational weight gain prior to glucose screening and the risk of gestational diabetes: a meta-analysis.

41. Phelan SM, Burgess DJ, Yeazel MW, Hellerstedt WL, Griffin JM, van Ryn M. Impact of weight bias and stigma on quality of care and outcomes for patients with obesity. Obesity Reviews. 2015 Apr;16(4):319-26.

42. Piché ME, Poirier P, Lemieux I, Després JP. Overview of epidemiology and 
contribution of obesity and body fat distribution to cardiovascular disease: an update. Progress in cardiovascular diseases. 2018 Jun 28.

43. da Silva M, Weiderpass E, Licaj I, Lissner L, Rylander C. Excess body weight, weight gain and obesity-related cancer risk in women in Norway: the Norwegian Women and Cancer study. British journal of cancer. 2018 Aug;119(5):646.

44. Sato F, Maeda N, Yamada T, Namazui H, Fukuda S, Natsukawa T, Nagao H, Murai J, Masuda S, Tanaka Y, Obata Y. Association of epicardial, visceral, and subcutaneous fat with cardiometabolic diseases. Circulation Journal. 2018 Jan 25;82(2):502-8.

45. Foright RM, Presby DM, Sherk VD, Kahn D, Checkley LA, Giles ED, Bergouignan A, Higgins JA, Jackman MR, Hill JO, MacLean PS. Is regular exercise an effective strategy for weight loss maintenance?. Physiology \& behavior. 2018 May 1;188:86-93. 